\title{
Facilitating Active Learning Engineering Courses with Tablet PC Note Taking Technology
}

\author{
Craig Scott, Pamela Leigh-Mack, Solomon Alao, Alicia Davis, \\ Yacob Astatke, and Schinnel Small \\ Department of Electrical and Computer Engineering \\ Morgan State University, Baltimore, Maryland
}

\begin{abstract}
This paper describes an investigation of a means to use technology to help students construct meaning through the use of the dimensions of Learning (DOL) pedagogical frame work. We use the tablet PC and specialized note taking software to facilitate the three minute pause technique and summarizing. This is done in an active learning environment and serves as a formative assessment for the class section being taught. These activities are done during the delivery of the performance tasks presented to a lower level pre-calculus course section. Details of the performance tasks, assessments and are discussed as well as the resulting impact of using tablet PCs as compared to laptops and conventional writing for note taking are discussed. Our results indicate although handwritten notes are generally preferred by most students, the tablet PC does have some advantages. Furthermore the users of the tablet PCs appeared to take better notes and benefit more from the summary exercise.
\end{abstract}

\section{Introduction}

Students and faculty at many academic institutions are finding innovative ways to use tablet PCs as enabling instruments to support learning ${ }^{1}$. Here at Morgan State University, our previous effort was directed at studying how technology has had an impact on student perception $^{2}$. Perception is the first dimension in our pedagogical framework. We have adopted the dimensions of learning pedagogical framework as the basis for our classroom teaching practices. The Dimensions of Learning (DOL) framework ${ }^{3}$ is a comprehensive model that uses what researchers and theorists know about learning to define the learning process. Its premise is that five types of thinking, or the five "dimensions of learning," are essential to successful learning. The framework ensures that instruction takes into account all five of the critical components of learning which include:

- Positive Attitudes and Perceptions about Learning;

- Thinking Involved in Acquiring and Integrating Knowledge 
- Thinking Involved in Extending and Refining Knowledge

- Thinking Involved in Using Knowledge Meaningfully

- Productive Habits of the Mind.

This work centers on ways to infuse the tablet PC technology within the second dimension; Thinking Involved in Acquiring and Integrating Knowledge. Specifically, we investigate a means to use technology to help students construct meaning. An important aspect of acquiring and integrating declarative knowledge is constructing meaning. Students draw upon prior knowledge and then link it to new knowledge during the declarative knowledge integration process. Most note taking research has been directed at understanding the roles of encoding and external storage. Encoding serves to increase the learner's attention and external storage serves to improve memory retention ${ }^{4}$. We use the Tablet PC and specialized note taking software to facilitate the three minute pause technique and summarizing ${ }^{5}$. This allows the student to shift from listening to reflecting and talking. The pause exercise is done in an active learning environment and serves as a formative assessment for the class section being taught. These activities are done during the delivery of performance tasks presented to a lower level precalculus course section. A subset of students in the classroom takes notes and shares notes in groups of two. The students are evaluated on their note taking skills by examining their notes, both individual and shared using a rubric and by questionnaires.

Technology in the form of electronic note taking has both advantages and disadvantages as compared to conventional note taking and are listed in Table 1 below:

\begin{tabular}{|l|l|}
\hline \multicolumn{1}{|c|}{ Advantages } & \multicolumn{1}{c|}{ Disadvantages } \\
\hline duplication & setup \\
\hline sharing & training \\
\hline distribution & volatility \\
\hline searching & duration limited (battery life $\sim 4-6 h r s)$ \\
\hline organization/revising & unnatural feel \\
\hline $\begin{array}{l}\text { supplemental materials photos, URLs, } \\
\text { applets/programs, diagrams etc. }\end{array}$ & \\
\hline
\end{tabular}

Table 1. Comparison of electronic and conventional note taking.

The research question posed in this work is can the tablet PC facilitate and enhance encoding and external storage functions during learning?

\section{Technology}

The note taking software, OneNote, harbors a rich set of features that can be exploited in an active learning environment. Students have the ability to share notes with specified users,

Proceedings of the 2005 American Society for Engineering Education Annual Conference \& Exposition Copyright (C) 2005, American Society for Engineering Education 
publish and email these notes to websites, search their handwritten notes and import PowerPoint or Word documentation for annotation in which the digital ink can be saved and referenced by author. Additionally, the instructor can grade electronic submissions with digital ink. To date, the tablet PC has proven to be a very useful tool as an instructional technology and is met with much enthusiasm by our students when encountered in the classroom environment. As a part of a Hewlett Packard Mobile Technology Initiative, six TC 1000 table PCs were assigned, by lottery, to six students in the class. The TC 1000 tablet PC features a 10.4 inch XGA LCD screen in a 1" x 10.8”x8.5” form factor, a pen stylus, $30 \mathrm{~Gb}$ hard drive, $1 \mathrm{GHz}$ Transmeta Crusoe processor and integrated 802.11b wireless connectivity. Typical battery life ranges from 4 to 6 hours under use. The classroom environment includes four Cisco 850 access points, and a 2000 lumen XVGA projection system. Typically this arrangement will accommodate 30 mobile users. The TC1000 is depicted in figure 1.

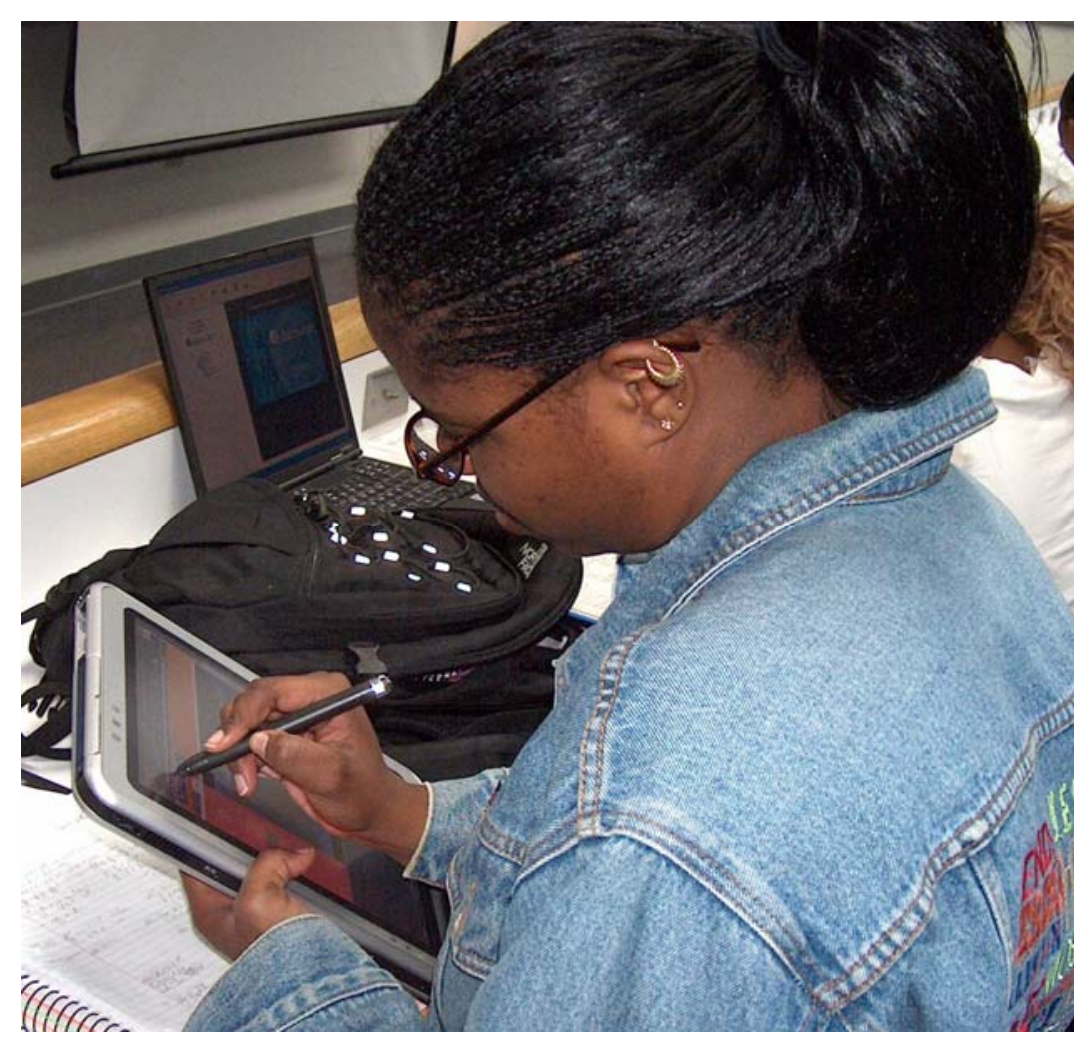

Figure 1. HP TC1000 tablet PC being used in the classroom

\section{Performance Tasks}

The engineering performance tasks are geared toward exposing freshmen engineering students to applications which apply precalculus mathematical concepts to focused problems

Proceedings of the 2005 American Society for Engineering Education Annual Conference \& Exposition Copyright (C) 2005, American Society for Engineering Education 
with an engineering context. The design and delivery of such tasks require careful planning. Most engineering applications assume familiarity with calculus. As a result the depth in which the subject matter is treated must be carefully thought out and explained. A team of four engineering professors met over the summer to create performance tasks for the Civil, Electrical, and Industrial Engineering areas. The performance task is outcome driven and is evaluated using a rubric. For our note taking study, a performance task involving music synthesis was chosen. A detailed account of this performance task is shown in appendix A.

\section{Description of the Note-Taking Experimental Procedure}

For the note taking experiment, the students of the class were divided into three groups. The first group consisted of nine students who would take notes on pen and paper. The second group consisted of four students who would take their notes on laptops that were provided. The third group consisted of five students who would take their notes on tablet PCs that were also provided. The distribution of laptops was based on the students' typing proficiency, whereas tablet PCs were distributed to students who expressed their interest in learning how to use the device and a lottery.

In each group, the students were paired, so that each student would be able to correspond with another person who also took notes in the same format. The students were instructed to take careful notes while the professor conducted the exercise, and were encouraged to use any creative means to ensure that they could record and display the notes as clear and organized as possible.

After a twenty minute task introduction, the students were then instructed to compare their notes to the partner with whom they were paired. As they compared, the students were also required to make annotations, if necessary, in a different color (or different writing utensil), so that the professor could recognize where note editing had taken place. The students who used the laptops and the tablet PCs were particularly instructed to use One Note software, which enabled the students to connect their computers so that they could share and compare their notes. The students were allowed five minutes to do this procedure (instead of three), after which they were to submit one paper per pair that would sufficiently represent the note taking abilities of both of the students. The notes submitted to the students would then be analyzed for clarity, organization and completeness.

The experiment was concluded with a short Likert scale survey (outlined below) in which the students could describe their note taking habits and express their opinion regarding this experience.

Proceedings of the 2005 American Society for Engineering Education Annual Conference \& Exposition Copyright (C) 2005, American Society for Engineering Education 


\section{Note Taking Questionnaire}

The questions in the survey were as follows:

1. While I am taking notes, I think about how I will use them later.

2. I understand the lecture and classroom discussion while I am taking notes.

3. I organize my notes in some meaningful manner (such as outline format).

4. I organize my notes to show the relative importance of the ideas.

5. I write legibly to make my notes easy to study later.

6. I edit notes for accuracy and legibility after class as soon as possible.

7. I review and edit my notes systematically.

8. I take notes on supplementary reading materials.

9. When reading, I mark or underline parts I think are important.

10. I prepare by reading assigned text and reviewing notes from the previous lecture.

11. I write more than the professor puts on the board or overhead.

12. The subtopics of the lecture are easy to see in my notes.

13. I can easily find things in my notes after I have taken them.

14. I include examples and significant details.

15. I find sharing my notes with others useful.

16. I regularly share and compare my notes with others.

If you had a computer - questions dealing with you opinions about how personal computing might affect the lecture experience.

Which of these input devices would you like to take notes with?

17. Paper and Pen or Pencil

18. Keyboard

19. Pointing Device (e.g. mouse, touchpad, trackball, etc.)

20. Stylus (electronic pen like or pencil like device)

21. What advantages might being able to take notes electronically have over your current method?

22. What disadvantages might being able to take notes electronically have compared to your current method?

23. Describe what you liked about your current note-taking experience (that occurs during class).

24. Describe what you disliked about your current note-taking experience (that occurs during class).

For questions 17 through 20, the responses were 1 to 4 , with 1 being least preferred and 4 being most preferred. Questions 21 through 24 were open ended questions. 


\section{Results}

To ascertain the impact of the tablet PC on the students note taking experience, the student responses to the questionnaire were used to exemplify any advantages and disadvantages as shown in Table 1. The chart in figure 3 illustrates a comparison of the Likert values for the overall class (including tablet PC users, notebook users and conventional paper and pencil users).

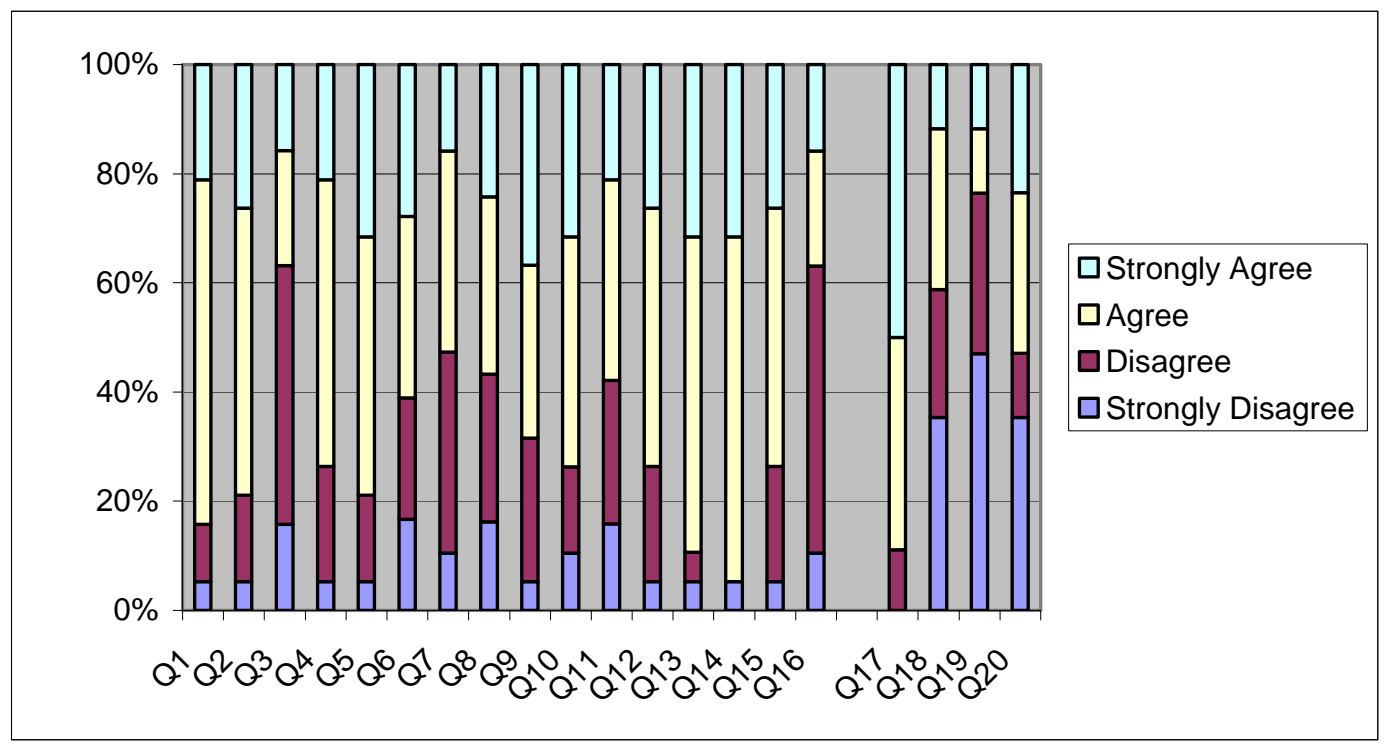

Figure 2. A comparison of the Likert values for the overall class.

It can be seen that overall the students feel positive about:

o Thinking about how they will use the notes later. (Q1)

o Understanding the lecture and classroom discussion while they taking notes. (Q2)

o Organizing their notes to show the relative importance of the ideas. (Q4)

o Writing legibly to make their notes easy to study later. (Q5)

o Marking or underlining parts they think are important. (Q9)

o Preparing by reviewing notes from the previous lecture (Q10)

o Organizing their notes so the subtopics of the lecture are easy to see. (Q12)

o Easily finding things in their notes after they have taken them. (Q13)

o Including examples and significant details. (Q14)

o Feeling that sharing their notes with others is useful. (Q15)

On the other hand they do not seem to think that they do a good job in:

o Organizing their notes in some meaningful manner (such as outline format). (Q3)

o Reviewing and editing their notes systematically (Q7)

o Taking notes on supplementary reading materials (Q8)

o Writing more than the professor puts on the board or overhead. (Q11)

Proceedings of the 2005 American Society for Engineering Education Annual Conference \& Exposition Copyright (C) 2005, American Society for Engineering Education 
o Regularly sharing and comparing their notes with others. (Q16)

To delve further, the average Likert results were tabulated for the three categories of student note takers and plotted against the results for the tablet PC user group. A comparative chart is shown in Figure3. The tablet PC group seemed to feel they were doing better at writing legibly, thinking about future uses of their notes, writing more than the professor puts on the board and sharing their notes with others. Although the tablet group prefers paper over the electronic media they rate the tablet as the second choice over the keyboard and mouse.

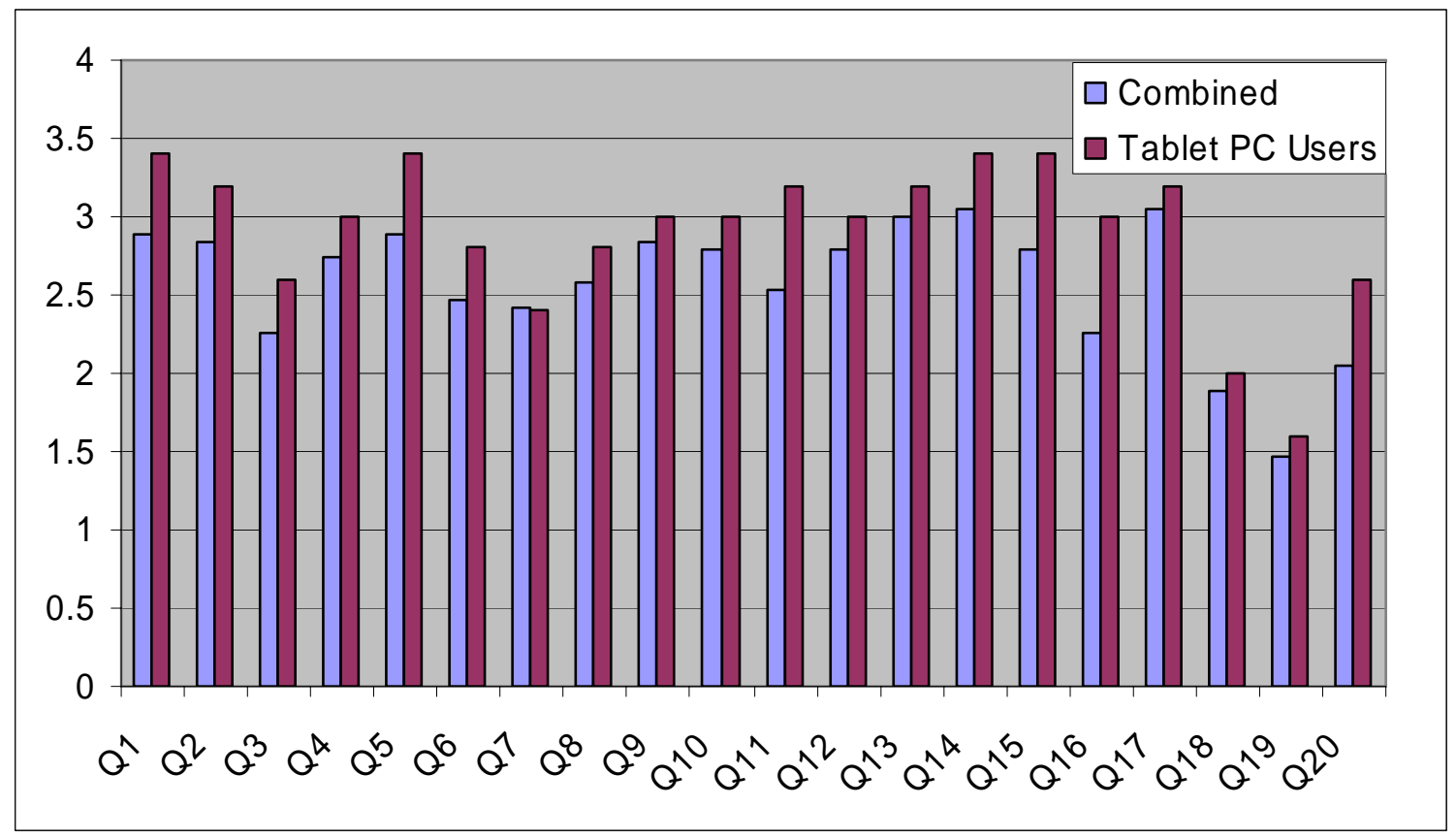

Figure 3. Average Likert results for the class aggregate and the tablet PC group.

Samples are shown representing notes captured from the tablet PC group (figure 4a.) and the note book group (figure 4b). It is quite impressive to see how the notebook users attempt to compensate with the touchpad for a lack of a good drawing input device. The tablet PC sample shows slightly better organization and flow. Free style comments indicate the major advantages of electronic notes are: freely duplicating them, organizing and reorganizing them, saving paper, sharing and neatness. The major disadvantages were: a demanding typing speed and equipment malfunction. 


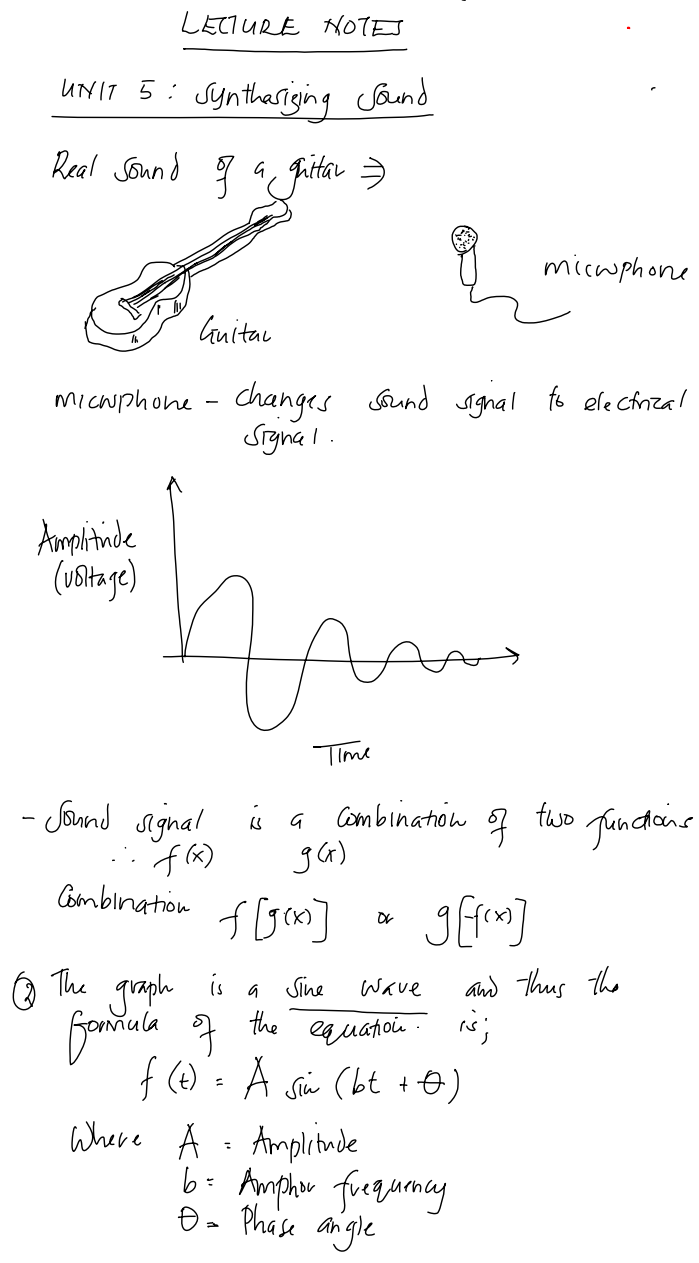

LAB: UNIT 5 - Synthesizing sounc

With a guitar you can use a microphone to record the sound of the guitar and changinc the sound to an electrical signal. Microphone changes sound signals to electrica signals

? How can we synthesize sound to make it sound as real as possible?
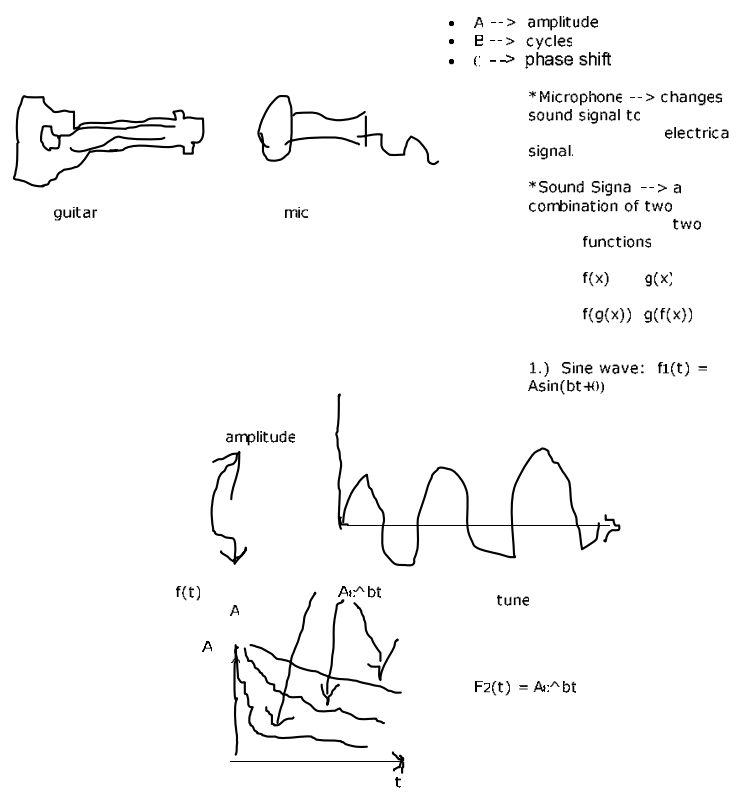

2.) Exponential formula: $F z(t)=A_{0} \wedge \mathrm{Bt}$

- $B=$ decay rate

$\begin{aligned} & T=\text { constant } \\ \text { A } & =\text { amplitude }\end{aligned}$

$: \quad:=2.1718 \ldots . . .$.

- $B<0$ (less than zero)

$\Rightarrow$ find the volume for $\mathrm{A} \& \mathrm{~B}$ using certain constants.

\section{Figure 4. Representative notes from: a) a tablet PC user and b) a notebook user.}

The results from pre and post testing for the performance task sessions were collected in an attempt to determine the impact of encoding and external storage during the note taking process on the ability to construct meaning. The learners were evaluated using a rubric with scoring levels between zero and two representing novice and expert practitioner levels respectively. The final scores and gain are plotted as bar charts in figure 5 . While the post test scores indicate a slight increase for the tablet PC users, the most significant difference can be seen in the gain results. The gain for the Tablet PC group represents a $62 \%$ increase over the total class gain. The conventional and notebook note takers scores remain near the class average. 


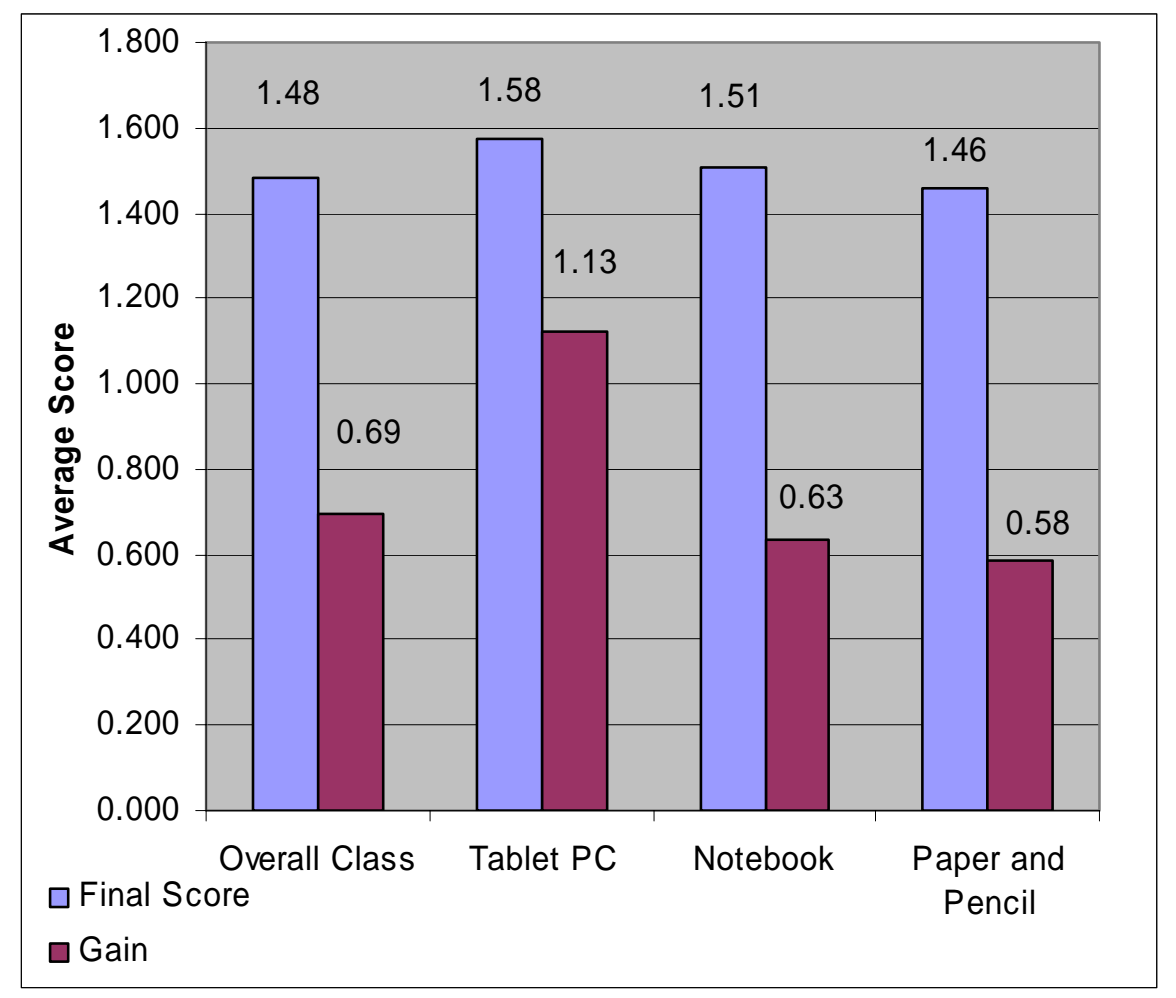

Figure 5. Performance task scores for different groups of note takers.

\section{Conclusion}

We have studied the impact of using mobile tablet PCs in a lower division pre calculus class. Our results indicate that the tablet is the preferred technology for taking notes other than paper and pencil. The students using the tablet PCs were able to practice note sharing and systematic organization more effectively than the other groups of note takers. There appears to be a noticeable impact of using tablet PCs and note taking software on the overall performance of the learners. These results appear encouraging; however larger samples are needed along with more extensive student training on general note taking and how to utilize the hardware and software more effectively.

\section{Bibliography}

1. http://www.rose-hulman.edu/news/articles/paperless.htm

2. Craig Scott, Pamela Leigh-Mack, Damian Watkins, Solomon Alao, Shurron Farmer "Assessing the Impact of Mobile Information Communications Technology on Student

Proceedings of the 2005 American Society for Engineering Education Annual Conference \& Exposition Copyright (C) 2005, American Society for Engineering Education 
Attitudes and Perceptions in an Urban Higher Education Environment, "2004 ASEE Annual Conference, Salt Lake City, Utah, June 20-23, 2004.

3. R.J. Marzano, D.J Pickering, D.E. Arredondo, G.J. Blackburn, R.S. Brandt, C.A. Moffett, , D.E. Paynter , Pollack, J.E., \& Whisler, J.S. Dimensions of learning: Trainers manual (2nd ed.). Alexandria, VA: Association for Supervision and Curriculum Development, 1997.

4. F.J. DiVesta and G.S. Gray, Listening and Note Taking. Journal of Educational Psychology, 63, 8-14, 1972.

5. Grant Wiggins and Jay McTighe, Understanding by Design,. Published by the Association for Supervision and Curriculum Development (ASCD), Alexandria, VA. 1998.

\section{Biographical Information}

CRAIG SCOTT is an Associate Professor of the Department of Electrical and Computer Engineering at Morgan State University. Dr. Scott received a B.S. in Electrical Engineering in 1979 from Howard University. He received his M.S.E.E degree from Cornell University in 1981 and a Ph.D. degree in 1991 from Howard University. His research interests include the development of advanced engineering visualization tools and courseware, materials characterization studies, and the simulation of semiconductor devices.

PAMELA LEIGH-MACK is an Associate Professor and Chair of the Department of Electrical and Computer Engineering at Morgan State University. Dr. Leigh-Mack received a B.S. in mathematics in 1980 from Virginia Union University. She received her B.S.E.E. and M.S.E.E degrees from Howard University in 1980 and 1982, respectively, and a Ph.D. in 1991 from the University of Delaware. Her research interests include pedagogical innovations and women in engineering issues.

SOLOMON ALAO is an Associate Professor of Teacher Education and Administration at Morgan State University. He received his B.S. degree in Recreation and Administration from Delaware State University in 1991 and his Ph.D. in Human Development (Ed-psych) from the University of Maryland in 1997. He was formerly a researcher at the National Reading Research Center (NRRC). The center conducted studies on reading, writing, science and history learning, assessment, and professional development. His research interests include human motivation and learning, student achievement motivation, conceptualization of knowledge, assessment, and curriculum leadership.

YACOB ASTATKE is an instructor in the Electrical and Computer Engineering Department at Morgan State University. He received his B.S.E.E. from Morgan State University, and his M.S.E.E. from Johns Hopkins University. His teaching interests include electric circuits, and communications theory. His research interests include wireless communication and web-based course development.

Proceedings of the 2005 American Society for Engineering Education Annual Conference \& Exposition Copyright (C) 2005, American Society for Engineering Education 
SCHINNEL SMALL is currently a D.Eng. candidate of the Department of Electrical and Computer Engineering at Morgan State. He received her B.S.E.E. degrees from Morgan State University in 2004. Her research interests include synthetic vision systems and network security.

\section{Appendix A.}

\section{Engineering Performance Task}

Pre-Calculus Unit 5 \& 7:

Exponential, Logarithmic and Trigonometric Functions Njage 8/6/04

\section{Engineering Topic}

Synthesizing sound

II. Learning Outcomes (DOL 2)

Declarative Knowledge. The student shall understand the basic shapes of exponential, natural logarithm as well as the inverse relationship between the two types of functions. Procedural Knowledge. The student shall be able to graph exponential functions and determine their significant features. The student shall be able to solve simple exponential and logarithmic equations.

\section{Thinking or Reasoning Processes}

\section{DOL 3: Extend and Refine}

Students will extend their knowledge of exponential, and logarithmic functions to applications involving synthesizing sound signals.

\section{DOL 4: Use knowledge meaningfully}

Students will use their knowledge of exponential, and logarithmic functions to describe and analyze engineering problems.

\section{Description of Performance Task}

\section{Engineering Context}


If you were to place a microphone next to a guitar and pluck one string, the voltage signal out of the mike would look something like that shown in Figure 1 above. The waveform can be described as the product of two basic types of waveforms. If you look carefully, you will notice

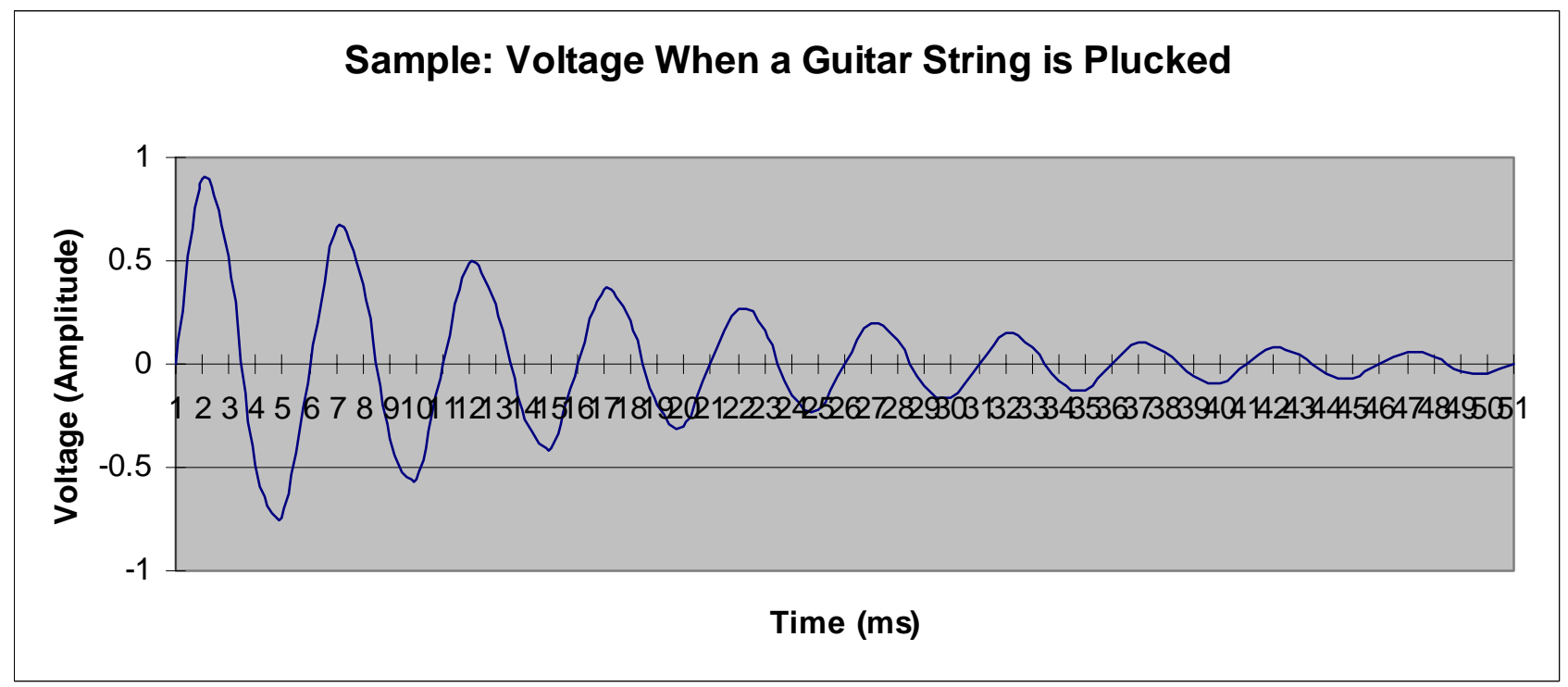

that the overall shape, or envelope, of the signal starts out high and gradually decays. This envelope represents the energy or loudness of the sound. The initial loudness depends on how hard the guitar string was plucked, the size and shape of its resonator as well as other factors. The rate of decay describes how long the sound persists, or hangs in the air. The envelope waveform is a decaying exponential like that shown in Figure 2 below. It can be expressed mathematically as $\mathrm{e}(\mathrm{t})=\mathrm{Ae}^{-\alpha \mathrm{t}}$, where $\mathrm{A}$ is the initial amplitude and $\alpha$ is the rate of decay.

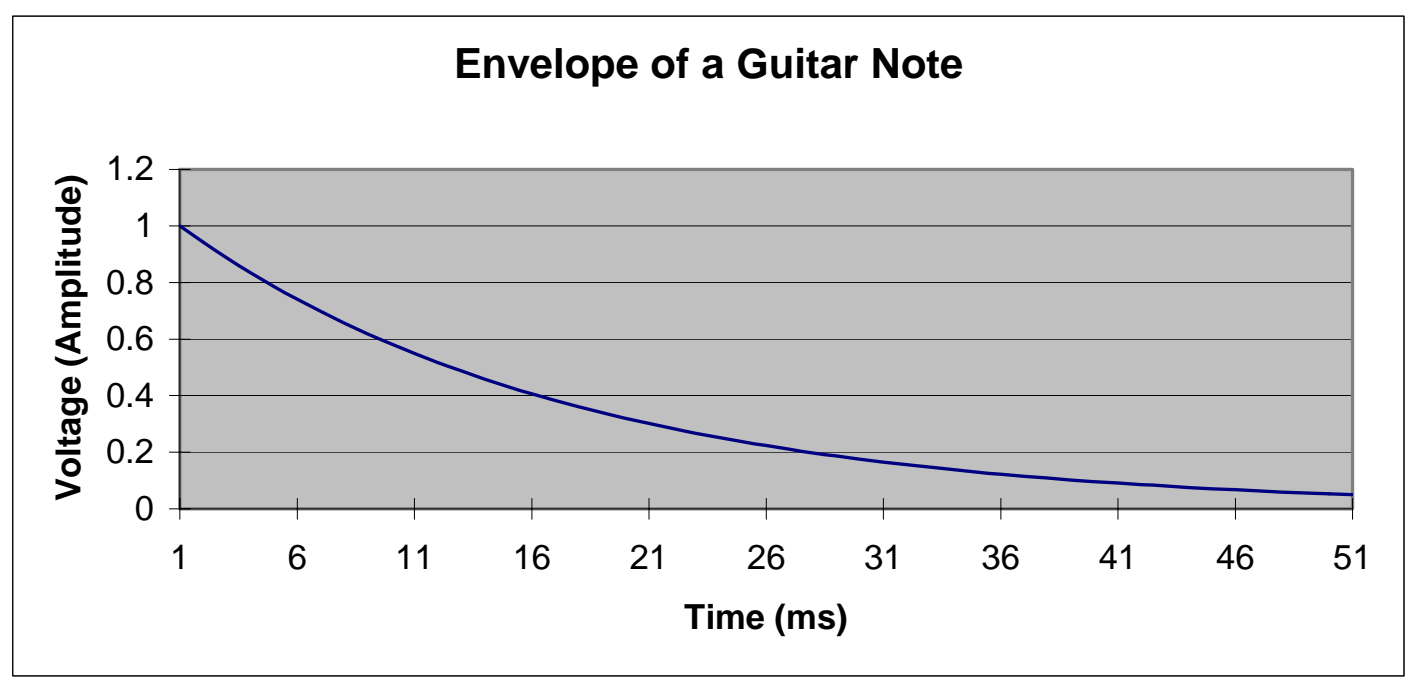

Within this envelope there is a repetitive (or periodic) oscillation. The rate of oscillation or frequency of the waveform is what you hear as the pitch or musical note. The middle-C note on

Proceedings of the 2005 American Society for Engineering Education Annual Conference \& Exposition Copyright (C) 2005, American Society for Engineering Education 
a piano, for example, produces a waveform with a frequency of about 262 cycles per second. These simple oscillating signals are called sinusoids and will be covered in great detail in Unit 7 later in this course.

Most natural (non-synthesized) musical sounds are created by the vibration of a structural element of an instrument such as a stretched string in a guitar, violin or piano, or a column of air in wind instruments. The vibrations produce standing waves of air pressure that travel to your ear where they are converted to electrical impulse and passed on to your brain.

In toys, video games, electronic keyboards, and automated voice response systems, as well as other applications, realistic sounds need to be generated from scratch, without the aid of actual instruments.

One main goal of sound synthesis is to electronically produce air pressure waves that sound as close as possible to naturally produced ones. To achieve this, it is first necessary to generate voltage signals similar to those produced when a microphone is held to the instrument.

\section{Directions to the student}

As a newly hired engineer at Terrific Toys for Tots, Inc., you have been assigned the job of creating sound effects for a new line of toys. You decide to start by synthesizing piano sound notes. In this task, we shall concentrate on the overall shape of the waveform. Discussion of the oscillations inside the envelope will be postponed until later. The first note you are to produce should have an initial amplitude (loudness) of $\mathbf{5}$ units (volts). After two seconds, the note should have decayed to a tenth of its initial value.

Assume that the note starts at time $t=0$ and its envelope can be expressed as $e(t)=A e^{-\alpha t}$.

1. Find A, and $\alpha$.

2. Plot the envelope signal $A \mathrm{e}^{-\alpha \mathrm{t}}$ using a time scale that shows most (at least $95 \%$ ) of the decay.

3. What will be the amplitude of the envelope one second into the note?

Clearly describe, in detail, all steps used to arrive at your solutions and explain all your answers.

\section{Mathematical Concepts}

The exponential function $\mathrm{e}(\mathrm{t})=\mathrm{A} \mathrm{e}^{-\alpha \mathrm{t}}$ has amplitude $\mathrm{A}$ at time $\mathrm{t}=0$ and decays for positive values of $\alpha$. The natural logarithm function is the inverse of the exponential function, that is, $\ln \left(\mathrm{e}^{\mathrm{x}}\right)=\mathrm{x}$ and $\mathrm{e}^{\ln \mathrm{x}}=\mathrm{x}$. Therefore, the value of $t$ at which the function $\mathrm{e}(\mathrm{t})=A \mathrm{e}^{-\alpha \mathrm{t}}$ decays to any arbitrary value can be found by taking the natural logarithm of both sides. 


\section{Rubric}

\begin{tabular}{|c|l|l|l|l|}
\hline Criteria & \multicolumn{1}{c|}{$\begin{array}{c}0 \\
\text { (Novice) } \\
\text { Makes an effort. } \\
\text { No understanding }\end{array}$} & $\begin{array}{c}1 \\
\text { (Apprentice) } \\
\text { On, good try. } \\
\text { Unclear if student } \\
\text { understands. }\end{array}$ & $\begin{array}{c}\text { 2 } \\
\text { (Practitioner) } \\
\text { Very good, clear. } \\
\text { Strong } \\
\text { understanding. }\end{array}$ & $\begin{array}{c}\text { (Expert) } \\
\text { Wow, awesome! } \\
\text { Excellent } \\
\text { understanding. }\end{array}$ \\
\hline $\begin{array}{c}\text { Ability to extract } \\
\text { functions } \\
\text { parameters from } \\
\text { graph features }\end{array}$ & $\begin{array}{l}\text { Unable to correctly } \\
\text { find A or } \alpha \text {, or to } \\
\text { outline a procedure } \\
\text { for finding them }\end{array}$ & $\begin{array}{l}\text { Correctly finds either } \\
\text { A or } \alpha \text { and provides } \\
\text { a few of the steps for } \\
\text { finding them }\end{array}$ & $\begin{array}{l}\text { Correctly finds both } \\
\text { A and } \alpha \text { and provides } \\
\text { some of the steps for } \\
\text { finding them }\end{array}$ & $\begin{array}{l}\text { Correctly finds A and } \\
\alpha \text { and provides a } \\
\text { detailed procedure for } \\
\text { finding them }\end{array}$ \\
\hline $\begin{array}{c}\text { Ability to plot a } \\
\text { graph of an } \\
\text { exponential given } \\
\text { its parameters }\end{array}$ & $\begin{array}{l}\text { Shows little or no } \\
\text { ability. No correct } \\
\text { data points. Axes not } \\
\text { labeled }\end{array}$ & $\begin{array}{l}\text { Some correct data } \\
\text { points, or some } \\
\text { labels incorrect or } \\
\text { missing }\end{array}$ & $\begin{array}{l}\text { Most data points } \\
\text { correct. Axes } \\
\text { properly labeled }\end{array}$ & $\begin{array}{l}\text { All points are correct. } \\
\text { Both axes correctly } \\
\text { labeled. }\end{array}$ \\
\hline $\begin{array}{c}\text { Communication } \\
\text { and explanation of } \\
\text { solution steps }\end{array}$ & $\begin{array}{l}\text { Un-organized and } \\
\text { hard to follow } \\
\text { solution steps }\end{array}$ & $\begin{array}{l}\text { Inconsistent and } \\
\text { incomplete } \\
\text { explanation and } \\
\text { organization }\end{array}$ & $\begin{array}{l}\text { Most solution steps } \\
\text { and values are well } \\
\text { explained }\end{array}$ & $\begin{array}{l}\text { Organization and } \\
\text { explanation of } \\
\text { solution steps is } \\
\text { consistent and } \\
\text { complete }\end{array}$ \\
\hline
\end{tabular}

\section{Performance Task Solution}

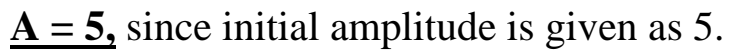

To solve for $\alpha$, we use the decay rate given as: "After two seconds, the note should have decayed to a tenth of its initial value." This translates to $\mathrm{e}(2 \mathrm{~s})=\mathrm{e}(0 \mathrm{~s}) / 10$, or $\mathrm{Ae}^{-\alpha 2}=\mathrm{Ae}^{-\alpha 0} / 10 \rightarrow$ $\mathrm{e}^{-\alpha 2}=1 / 10 \rightarrow \mathrm{e}^{\alpha 2}=10 \rightarrow \ln \left[\mathrm{e}^{\alpha 2}\right]=\ln [10] \rightarrow 2 \alpha=\ln [10] \rightarrow \alpha=\ln [10] / 2 \rightarrow$

\section{$\underline{\alpha=1.151292546497}$}

$\omega=2 \pi \mathrm{f}=2 \pi 262=1646.194550481$ 


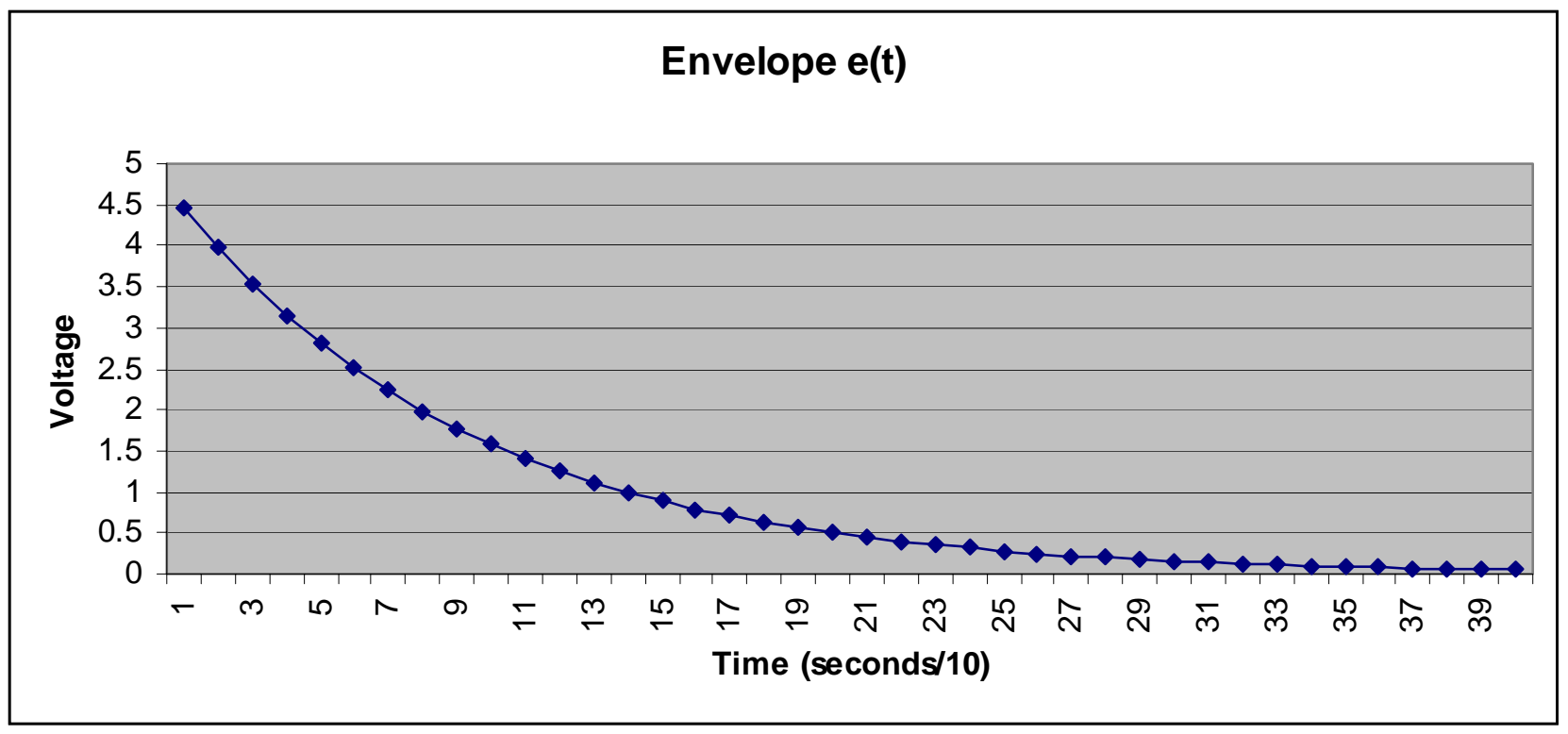

Proceedings of the 2005 American Society for Engineering Education Annual Conference \& Exposition Copyright (C) 2005, American Society for Engineering Education 